Journal of Social Issues, Vol. 48, No. 4, 1992, pp. 137-160

\title{
The Social Amplification of Risk: Theoretical Foundations and Empirical Applications
}

\author{
Ortwin Renn \\ Clark University \\ William J. Burns \\ University of lowa \\ Jeanne X. Kasperson and Roger E. Kasperson \\ Clark University \\ Paul Slovic \\ University of Oregon
}

The social experience of risk is not confined to the technical definition of risk, i.e., the product of probability and magnitude. What human beings perceive as threats to their well-being is influenced by their values, attitudes, social influences, and cultural identity. This article introduces the framework of social amplification of risk, which integrates the technical assessment and the social experience of risk. This viewpoint proposes that events pertaining to hazards interact with psychological, social, institutional, and cultural processes in ways that can heighten or attenuate individual and social perceptions of risk and shape risk behavior. An empirical study investigated the functional relationships among five sets of variables that enter into the amplification process: physical consequences, the amount of press coverage, individual layperson perceptions, public responses, and the socioeconomic and political impacts. It found that

This study is based upon work supported in part by the National Science Foundation under grants No. SES-8915711, SES-8722511, SES-8912104, and SES-8915711. The government has certain rights to this material. We thank Srinivas Emani for his valuable contributions to this study.

Correspondence regarding this article should be addressed to Ortwin Renn, CENTED, Clark University, Worcester, MA 01610. 
perceptions and social responses are more strongly related to exposure to risk than to its magnitude.

Modern society has been preoccupied with the notion of risk (Beck, 1986; Short, 1984). Advances in science and technology have enabled societies to accelerate the speed of technological change, to extend the scope and magnitude of human interventions into nature, and to affect individual lifestyles and social structures. This process has been accompanied by a major societal effort to assess, stimulate, control, and mitigate the potential consequences of this rapid change. Although two decades of research have created a substantial base of knowledge about how people and social institutions perceive and respond to risk, we lack a comprehensive concept of the social experience of risk, i.e., the social processing of uncertainty and the perception and evaluation of expected consequences related to an event or activity (Luhmann, 1990).

The risk field is a patchwork of many different schools and perspectives. Traditional technical risk analysis focuses narrowly on the probability of events and the magnitude of consequences (Freudenburg, 1988). However, what human beings perceive as threats to their well-being, and how they evaluate probabilities and magnitudes of unwanted consequences, are less a question of predicted physical outcomes than of values, attitudes, social influences, and cultural identity (Douglas \& Wildavsky, 1982, p. 38).

Risk perception research has revealed that contextual factors shape individual risk estimations and evaluations (Renn, 1990; Slovic, 1987). Identification of these factors, such as voluntariness, personal ability to influence risks, familiarity with the hazard, and catastrophic potential, provides useful information about the elements that individuals consider in constructing their interpretation of risks. In addition, analyses of people's heuristics in making inferences have shed some light on how risk information is generalized and evaluated intuitively (Kahneman \& Tversky, 1979). These psychological studies fail to explain, however, why individuals attend to certain characteristics of risks and ignore others. Furthermore, in focusing only on the individual as an information processor, these studies exclude from the analysis the social and cultural variance of risk interpretations.

Sociological analysis provides some further insights into the social and organizational factors that influence risk experiences (Clarke, 1989; May, 1989). Some studies focus on the organizational capability of risk management institutions to cope with large-scale risks and to function in the face of competing demands from various social groups (Clarke, 1989; Freudenburg, 1989; Perrow, 1984). Others attempt to identify social influences in the formation and change of attitudes towards risk-bearing activities or technologies (Gould et al., 1989; Short, 1984, 1989). Some aspects such as perceived fairness in the distribution of risks and benefits, have gained special attention (Kasperson \& Kasperson, 1983; 
MacLean, 1987; Rayner \& Cantor, 1987). More theoretically oriented studies have emphasized the social construction of risk interpretations and their relationship to different types of knowledge acquisition, social interests, and cultural values (Bradbury, 1989; Dietz, Stern, \& Rycroft, 1989; May, 1989; Otway \& von Winterfeldt, 1982). These sociological studies have been valuable and helpful for understanding the variability of risk interpretations among different groups and for pointing out the organizational problems that impede effective risk management and control and thus can aggravate the potential outcomes of risks (Freudenburg, 1989; Short, 1989). However, they remain scattered and often fragmented.

Coherence and plausibility are both characteristics of the cultural approach to risk (Douglas \& Wildavsky, 1982; Rayner, 1987; Schwarz \& Thompson, 1990). According to this approach, cultural beliefs and worldviews determine how people experience and interpret risks. A key focus of this theory is on two cultural prototypes: the entrepreneurs and the egalitarians. Entrepreneurs tend to regard risks as opportunities for development, whereas egalitarians tend to perceive risks as threats to their lifestyle and values. The claim that risk responses are a function of cultural belief systems has drawn fire from many analysts (cf. Johnson, 1987; Nelkin, 1982). First, depending on the social role they play, individuals may belong to several different cultural groups. Second, being a member of one cultural group does not preclude the capability to understand and accept the rationales of other groups as different but equally legitimate ways of dealing with the issue. Third and most important, empirical proof for the existence of these groups is still lacking. (So far they have been made plausible only by using empirical evidence as an illustration of these value patterns.)

From this brief review it is evident that a novel and integrative framework is necessary to analyze the social experience of risk and to study the dynamic processing of risks by the various participants in a pluralistic society. This article outlines such an approach and reports on initial empirical investigations to test the theoretical assumptions.

\section{The Concept of the Social Amplification of Risk}

\section{Defining the Concept}

In 1988, Kasperson and colleagues proposed a novel approach to study the social experience of risk. The concept of social amplification of risk is based on the thesis that events pertaining to hazards interact with psychological, social, institutional, and cultural processes in ways that can heighten or attenuate individual and social perceptions of risk and shape risk behavior. Behavioral patterns, in turn, generate secondary social or economic consequences that extend far beyond direct harm to humans or the environment, including significant 
indirect impacts such as liability, insurance costs, loss of trust in institutions, or alienation from community affairs (Kasperson et al., 1988).

Such secondary effects often trigger demands for additional institutional responses and protective actions, or conversely (in the case of risk attenuation), place impediments in the path of needed protective actions. In accordance with the metaphor of amplification in the processing of electronic signals, "amplification" is used here to include both intensifying and attenuating signals about risk. Thus, alleged overreactions of target audiences receive the same attention in the model as alleged "downplaying" (see the critical remarks about the focus on overreactions in Needleman, 1987; Rayner, 1988).

Some terms of this model need further explanation. In the social amplification framework, risk is conceptualized partly as a social construct and partly as an objective property of a hazard or event (Short, 1989, p. 405). To treat risk as both an objective property and a social construct avoids the problems of total relativism on one hand and of technological determinism on the other hand. Manifestations of risk, i.e., accidents or releases of harmful substances, are called "hazardous events." Hazardous events remain largely irrelevant in the social context unless they are observed by human beings and communicated to others (Luhmann, 1986, p. 63). The consequences of these communication efforts may lead to other physical transformations, such as changes in technologies, methods of land cultivation, or the composition of water, soil, and air. The experience of risk is therefore not an experience of physical harm, but the result of a process by which individuals or groups learn to acquire or create interpretations of hazards. These interpretations provide rules of how to select, order, and often explain signals from the physical world.

\section{The Process of Amplification}

Figure 1 illustrates the process of amplification. The amplification process starts with either a physical event (such as an accident) or the recognition of an adverse effect (such as the discovery of the ozone hole). In both cases, individuals or groups select specific characteristics of these events or aspects of the research findings, and interpret them according to their perceptions and mental schemes. These interpretations are formed into a message, and communicated to other individuals and groups (Renn, 1991). Individuals or groups collect and respond to information about risks, and act as "amplification stations" through behavioral responses or communication. Amplification stations can be individuals, groups, or institutions. Amplification differs among individuals in their roles as private citizens, and in their roles as employees or members of social groups and public institutions.

With respect to the individual stations of amplification, the perception and amplification process can be subdivided into eight steps (Table 1). This cognitive 


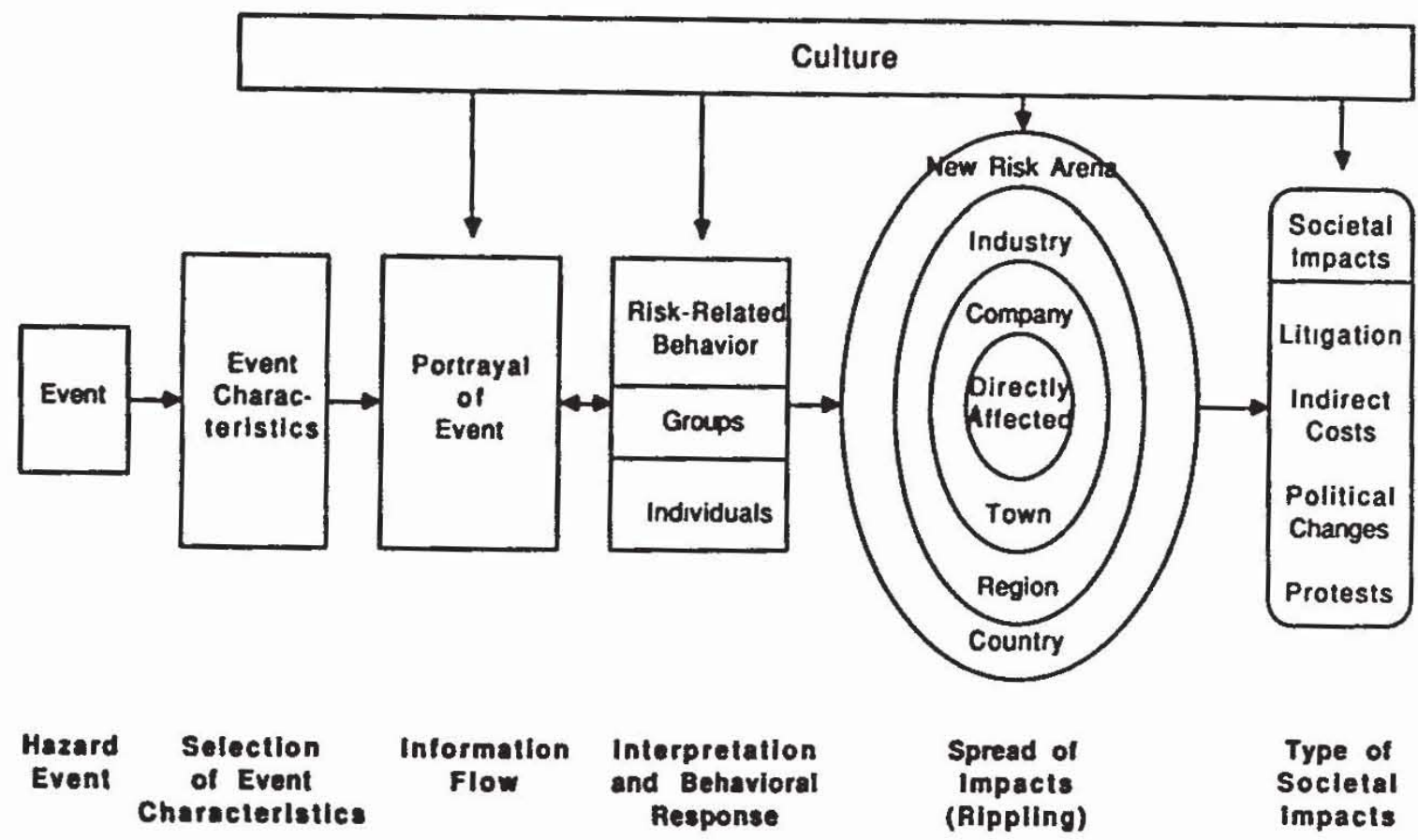

Fig. 1. Simplified representation of the social amplification of risk concept.

process has to be supplemented further by emotional and subconscious processes that filter incoming messages and codetermine their evaluation (Lee, 1986; Renn, 1984, pp. 111-115).

The decoding and evaluation process determines the receiver's selection of significant information. The components of the decoded message that are inconsistent with previous beliefs, or that contradict values to which the receiver feels attracted, are ignored or attenuated. If the message is attractive or consistent with previous beliefs, the signals are intensified. The process of receiving and processing risk-related information by individuals is well researched in the risk perception literature (Covello, 1983; Renn, 1990; Slovic, 1987). But this is not sufficient: individuals act also as members of larger social units that codetermine the dynamics and social processing of risk.

These larger social units are called the social stations of amplification. Individuals in their roles as members or employees of social groups or institutions do not simply follow their personal values and interpretative patterns, but they also perceive risk information according to the rules of their home organization or group. These rules are derived from professional standards and rules (characteristic for scientific communities, interest groups, media editors, political institutions, etc.); institutional interests, functions, and foci; rules and role expectations pertaining to the specific position of the receiver; and interpretation of those role expectations by the holder of the position.

The role-specific reception factors are internalized and reinforced through education and training, identification with the goals and functions of the respec- 
Table 1. Steps in Individual Perception of Information

Steps

Description

1. Passing through attention filters

2. Decoding of signals

3. Drawing inferences

4. Comparing the decoded messages with other messages

5. Evaluating messages

6. Forming specific beliefs

7. Rationalizing belief system

8. Forming a propensity to take corresponding actions
Selecting and further processing signals from the environment, other individuals, and the media

Deciphering the meaning of the signals (investigating factual content, sources of information, explicit or implicit inferences, value statements, overt and hidden intentions of information sources and transmitters, and cues to assign credibility of information and information source)

Arriving at conclusions about the allegedly revealed intentions of the source and the transmitter, employing intuitive heuristics (common sense reasoning) for generalizing the information received, and using symbolic cues for judging the seriousness of the information

Analyzing the meaning of the message in the light of related messages from other sources or previous experience

Rating the importance, persuasiveness, and potential for personal involvement on the basis of the perceived accuracy of the message, the potential effect on one's personal life, the perceived consistency with existing beliefs (to avoid cognitive dissonance), reference group judgments (to avoid social alienation), and personal value commitments

Generating or changing beliefs about the subject of the message or to reassert previously held beliefs

Sorting and reinterpreting beliefs in order to minimize cognitive dissonance

Generating intentions for future actions that are in accordance with the belief system

tive institution, belief in the importance and justification of the produced output, and positive rewards (promotion, salary increases, symbolic honors) and negative punishments (downgrading, salary cuts, disgracing).

The behavioral and communicative responses are likely to evoke secondary effects that extend beyond the people directly affected by the original hazard event. Secondary impacts include the following:

-enduring mental perceptions, images, and attitudes (e.g., antitechnology attitudes, alienation from the physical environment, social apathy, or distrust of risk management agencies);

-impacts on the economy (e.g., drop in business sales, residential property values, and tourism; increased liability and insurance costs);

-political and social pressure (e.g., political demands, changes in political climate and culture; social disorder);

-changes in the physical nature of the hazard (e.g., feedback mechanisms that reduce or heighten the potential impact of the hazard); 
-repercussions on other technologies and activities (e.g., higher or lower level of acceptance).

Secondary impacts are, in turn, perceived by social groups and individuals so that another stage of amplification may occur to produce third-order impacts. The impacts may spread or "ripple" to other parties, distant locations, or other risk arenas (Figure 1). Each order of impact will not only disseminate social and political effects, but may also trigger (in risk amplification) or hinder (in risk attenuation) positive changes for risk reduction.

\section{Applicability of the Social Amplification Concept}

The concept of social amplification of risk provides a framework for the analysis of risk experience, and constitutes a dynamic framework that facilitates the systematic interpretation of empirical data and attempts to integrate the existing perspectives on risk. Ideally, the concept should be used to define new research areas, generate hypotheses and ideas for studying risk experiences, identify links among different research perspectives, and provide a terminology that allows comparisons of results from varying disciplines and research camps. Our hope is that the concept should overcome fragmentation but not impede diversity. One review described the social amplification concept as a "framework that, like a net, is useful for catching the accumulated empirical findings, and that, like a beacon, can point the way to disciplined inquiry" (Machlis \& Rosa, 1990 , p. 164).

The concept of social amplification is not a theory in the classical sense. However, it provides a conceptual framework for selecting, ordering, and classifying social phenomena, and suggesting theoretical relations that can be investigated empirically. The usefulness of the concept lies in its analytical strength and ability to generate hypotheses, and to explain social responses to risk that were impossible or difficult to explain in the framework of competing concepts (such as the psychological or cultural approaches). The framework has been used to generate empirical research since its introduction in 1988 (cf. Freudenburg, 1989; Kasperson et al., 1989; Machlis \& Rosa, 1990; Renn, 1991). Nonetheless, it is too early to draw conclusions about its usefulness, applicability, and limits. The following section describes a major empirical study based on the social amplification framework.

\section{An Empirical Study of the Social Amplification Concept}

\section{Study Design and Data Collection}

Drawing upon the concept of social amplification of risk, we investigated the functional relationships among five sets of variables that enter into the ampli- 
fication process. The first class of variables included the physical consequences of 128 hazardous events (events that exposed humans or the environment to physical harm); the second class involved the amount of press coverage about these 128 events; the third class entailed the individual layperson perceptions with respect to these events; the fourth class described the public responses (individual behavior intentions and group mobilization potential) to these hazards; and the fifth class contained the socioeconomic and political impacts. In accordance with the social amplification concept, we hypothesized that the socioeconomic and economic effects were the dependent variables, whereas perceptions, individual and group responses, and media coverage were the predictor variables. These predictor variables would also be influenced by the physical consequences. The objective of the study was to examine the structure of causal relationships among these classes of variables, and to investigate which of the predictor classes and which variables within each class exerted the most prominent influence on the primary and secondary impacts of the events. Figure 2 illustrates this structure among the variable classes.

Data regarding the five classes of variables were collected and compiled in two phases, over a period of two years. First, the research team selected 128 hazardous events, and collected data about their physical impacts, about print media coverage, about the perception of these events in the eyes of nonaffected citizens, about potential social group mobilization, and about the political and socioeconomic effects of these events.

The 128 hazards selected for this study were chosen by the research team on the basis of the technological hazard taxonomy suggested by Hohenemser, Kates, \& Slovic (1983). The selected taxonomy grouped hazard events into five classes: biocidal, persistent/delayed effects, rare catastrophes, threats to life, and global/diffuse; it was augmented by special samples of radiological and natural hazards. First, hazards were selected within each class, and then individual hazard events were chosen to represent these hazards. Table 2 lists the classes, the hazard subcategories, and the number of events selected in each category.

Once the hazard events were identified and classified, we used the entries in the New York Times Index to investigate their coverage in NEWS, a group file in the Nexis data base. The NEWS search yielded information to construct three variables: the total number of stories pertaining to each event, the duration of coverage for each event, and the "half-life," i.e., the period of time by which half of the total stories on each event had appeared.

The physical consequences of these 128 events were estimated by expert judgment and literature review. Three expert judges (a physicist, a chemist, and a geographer) rated four aspects of all events on a $\log$ scale from 1 to 9 , using risk assessments and impact analyses from the relevant literature whenever possible. The three judges first rated the events individually and then tried to reach a consensus. The four scales used for this assessment were human exposure to the 


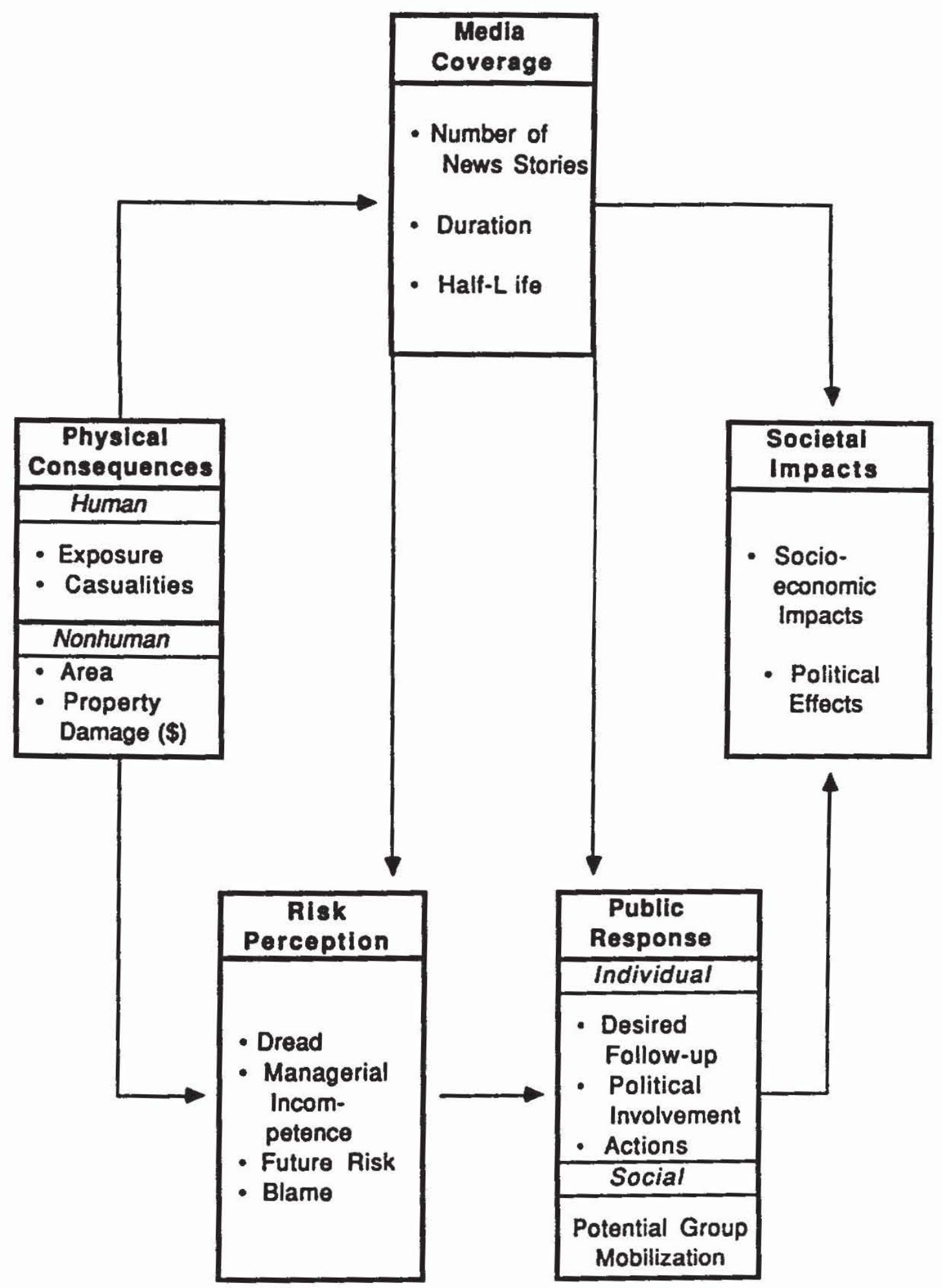

Fig. 2. Hypothetical model of causal relationships.

risk agent, magnitude of human casualties, amount of area affected by the hazard event, and the dollar amount of direct nonhuman damage.

Data pertaining to people's perceptions of risk and their likely responses were obtained by surveying students at the University of Oregon. In accord with the psychometric paradigm (Renn, 1990; Slovic, 1987), standard scales such as 
Table 2. Hazard Events Data Base

\begin{tabular}{|c|c|}
\hline Hazards & Effects (and number of events) \\
\hline \multicolumn{2}{|l|}{ Biological hazards (18) } \\
\hline Vaccines & Adverse health effects ( 3 ) \\
\hline Chain saws & Injury and/or death (3) \\
\hline Handguns & Injury and/or death (4) \\
\hline Bacterial contaminations & Morbidity and/or mortality (4) \\
\hline Pesticide use & Adverse environmental effects (4) \\
\hline \multicolumn{2}{|l|}{ Persistent/delayed hazards (16) } \\
\hline Mercury releases & Toxic effects (3) \\
\hline Benzene releases & Toxic effects (3) \\
\hline Radon emission & Toxic effects (3) \\
\hline Chemical waste disposal & Adverse health effects (4) \\
\hline Lead emissions & Chronic health effects (3) \\
\hline \multicolumn{2}{|l|}{ Rare catastrophes (19) } \\
\hline Airplane crashes & Injury and/or death (3) \\
\hline Dam failures & Injury and/or death (4) \\
\hline Chemical releases & Toxic effects (4) \\
\hline Explosions & Injury and/or death (5) \\
\hline Building collapses & Injury and/or death (3) \\
\hline \multicolumn{2}{|c|}{ Threats to life ("common killers") (19) } \\
\hline Smoking & Chronic effects/death (3) \\
\hline Asbestos use & Chronic effects/lung cancer (5) \\
\hline Automobile accidents & Injury and/or death (3) \\
\hline Household/hotel fires & Injury and/or death (5) \\
\hline Falls & Injury and/or death (3) \\
\hline \multicolumn{2}{|l|}{ Global diffuse (17) } \\
\hline $\mathrm{CO}_{2}$ emissions & Climatic change (3) \\
\hline Dioxin release & Toxic effects (4) \\
\hline Nuclear weapons testing/fallout & Injury and/or chronic effects (3) \\
\hline Ozone depletion & Environmental effects (3) \\
\hline Acid rain & Environmental effects (4) \\
\hline \multicolumn{2}{|l|}{ Natural hazards (20) } \\
\hline Lightning & Injury and/or death (4) \\
\hline Floods & Injury and/or death (4) \\
\hline Blizzards/snowstorms & Injury and/or death (3) \\
\hline Drought & Injury and/or death (3) \\
\hline Mud slides & Injury and/or death (2) \\
\hline Earthquakes & Injury and/or death (4) \\
\hline \multicolumn{2}{|l|}{ Radiological hazards (19) } \\
\hline Accidents & Radiation release (9) \\
\hline Nuclear waste facilities & Incidents (3) \\
\hline Transportation accidents & Damage to casks or radiation release (3) \\
\hline Uranium mining or enrichment & Radiation release (3) \\
\hline Others & Unsafe practices (1) \\
\hline
\end{tabular}

ones measuring people's assessment of seriousness, familiarity, and dread were accompanied by several new scales. These scales were constructed to measure, among other concepts, perceived managerial (in)competence (manageability); the assignment of blame, to either an institution or an individual, for causing or aggravating the hazardous event (blame); and the preferred way for society to 
handle the risk to avoid future occurrences of the respective hazard event (future risk). All respondents were asked to rate the 128 hazard events as described in the New York Times Index on a 7-point or 9-point scale for each characteristic. Ratings for each event on each variable were then averaged across respondents.

In addition to perception, the social amplification concept emphasizes the importance of both individual and social actions. Since all these events occurred in the past, it was considered infeasible to reconstruct the behavioral responses of individuals or social groups during the time period when the hazard event occurred. On the individual level, instead of the actual behavior of affected citizens, we substituted behavioral intentions of our survey respondents (in Oregon) by asking for their hypothetical responses had they had been exposed to each hazard event. The behavioral intention measures included desired follow-up coverage, potential for personal political involvement, and potential for personal action.

On the social group level, we asked two groups of university faculty members, experts in the social sciences, to rate the expected social mobilization potential of the event on a scale from 0 to 10 . Consensus among the experts in each group was reached by an iterative Delphi process, which is described in the next paragraph. The validity of this procedure was tested by comparing the assessments of the first group with the assessments of the second group. Substantial differences between these two groups called into question the validity of the measurements of social group mobilization. We decided to omit this variable from our aggregate analysis until we can obtain more valid indicators and test their replicability.

The political and socioeconomic consequences (societal impacts) were also difficult to measure and could not be assessed directly. We therefore collected all information available in the news media about the events' potential economic and political repercussions, and conducted a group Delphi procedure, a process of calibrating group judgments in iterative sessions (Renn \& Kotte, 1984; Webler, Levine, Rakel, Renn, in press). The participants were 12 experts from the fields of risk analysis, journalism, law, and politics. In the first round, three experts were randomly assigned to each of four groups, and each group was then asked to rate, on a scale from 0 to 10 , each event in terms of both political and socioeconomic impacts. All background information was provided with the case description. In a subsequent plenary session, groups with the highest or lowest score for each event had to provide arguments justifying their judgment. After an extensive discussion of these arguments, new groups were formed (systematically altering group composition so that each individual worked with new group members in each consecutive round) and asked to repeat the exercise under the constraint that group scores could not exceed the range of scores given in the first round. This procedure of forming new small groups was repeated several times until individual group scores did not differ by more than two scale points on the 
scale from 0 to 10 . The average scores for the four groups then served as data entries for further analysis.

In order to test the reliability of the group Delphi procedure, we repeated the entire exercise with another independent set of 12 experts coming from similar fields of expertise. These experts were given the same information and asked to perform identical tasks as before. The results of the two Delphi processes were so close that, with a probability of $99 \%$, both groups were measuring the same construct. We thus concluded that this Delphi method was a reliable instrument to measure socioeconomic and political impacts. Whether the method also provided valid results, we were not able to test formally. Table 3 lists all variables and describes their composition and method of elicitation.

The processing of so many variables requires selection of the appropriate statistical tools. In addition to examining simple correlations, our interest was to use the theoretical model of social amplification as a heuristic tool to model the relationships among the empirically generated variables. Confirmatory multivariate methods are well suited for this task, since the analyst must make explicit theoretical and measurement assumptions that can be tested statistically. Among the many multivariate procedures available, covariance structure analysis was used because it allows the researcher to investigate the relationships among and the predictors of variables (latent or observed). When multiple measures of theoretical constructs are available, this modeling procedure also permits the assessment of reliability and construct validity (for more details refer to Burns, 1991).

\section{Results of the Study}

What kind of relations were found among the key variables? Table 4 includes the simple correlations of all relevant variables, showing the strength of linear relationships between the variables. The variables are grouped in accordance with the hypothetical model illustrated in Figure 2. For example, exposure, casualties, area, and property damage are placed together because they relate to the physical consequences of a hazardous event. However, these four variables were not highly related, with correlations ranging in magnitude from .07 to .58 . The correlation between extent of exposure and magnitude of casualties was only .19 , which indicates that the two variables measured a different dimension of physical consequences. Exposure may represent potential danger, whereas casualties are related to actual harm.

The variables measuring risk perception were slightly more related to each other, with correlations ranging from .31 to .61 . This degree of relationship suggests that these measures also included more than one dimension of people's perception of risk. The same was true for individual response (behavioral intention) and potential for social group mobilization. For example, the correlation 
Table 3. Description of Variables in the Model

\begin{tabular}{|c|c|}
\hline Variable name & Description \\
\hline \multicolumn{2}{|l|}{ Physical consequences } \\
\hline Exposure & The number of people exposed to harm by a hazard event \\
\hline Area ${ }^{a}$ & The amount of area exposed to harm by a hazard event \\
\hline Casualties $^{a}$ & The number of people injured or killed by a hazard event \\
\hline Property damages ${ }^{a}$ & The financial damage done to property by a hazard event \\
\hline \multicolumn{2}{|l|}{ Media coverage } \\
\hline$N$ Stories ${ }^{b}$ & $\begin{array}{l}\text { The number of follow-up news stories generated by a hazard } \\
\text { event }\end{array}$ \\
\hline Duration $^{b}$ & $\begin{array}{l}\text { The number of days between the first and last news story re- } \\
\text { corded }\end{array}$ \\
\hline Half-life ${ }^{b}$ & The number of days until half the news stories were generated \\
\hline \multicolumn{2}{|r|}{ 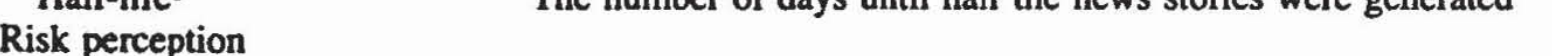 } \\
\hline Future risk ${ }^{c}$ & $\begin{array}{l}\text { Degree to which other people are at risk of experiencing harm } \\
\text { from future events of this type }\end{array}$ \\
\hline Dreadc & $\begin{array}{l}\text { Degree to which the public believes a hazard is associated with } \\
\text { catastrophic consequences }\end{array}$ \\
\hline $\begin{array}{l}\text { Managerial incompe- } \\
\text { tence }^{d}\end{array}$ & $\begin{array}{l}\text { Degree to which the public believes that a hazard event implies } \\
\text { that similar risks are being managed incompetently }\end{array}$ \\
\hline Blamed $^{d}$ & $\begin{array}{l}\text { Degree to which the public blames industry, regulatory agencies, } \\
\text { or the government for a hazard event }\end{array}$ \\
\hline \multicolumn{2}{|l|}{ Public response } \\
\hline Follow-up ${ }^{d}$ & $\begin{array}{l}\text { Degree to which the public desires the media to investigate and } \\
\text { report stories about a hazard event }\end{array}$ \\
\hline Political involvement ${ }^{d}$ & $\begin{array}{l}\text { Degree to which the public is willing to become politically in- } \\
\text { volved to reduce future risks posed by a hazard event }\end{array}$ \\
\hline Actiond & $\begin{array}{l}\text { Degree to which the public is willing to become actively in- } \\
\text { volved (e.g., joining an action-oriented group) to reduce fu- } \\
\text { ture risks posed by a hazard }\end{array}$ \\
\hline $\begin{array}{l}\text { Potential for social } \\
\text { mobilizatione }\end{array}$ & $\begin{array}{l}\text { Degree to which experts judge the event is likely to mobilize so- } \\
\text { cial groups beyond local boundaries. }\end{array}$ \\
\hline \multicolumn{2}{|l|}{ Societal impact } \\
\hline Political effectse & $\begin{array}{l}\text { Degree to which the hazard event generates political attention by } \\
\text { public officials. }\end{array}$ \\
\hline Socioeconomic impacte & $\begin{array}{l}\text { Degree to which the hazard event generates socioeconomic im- } \\
\text { pacts (e.g., loss of sales, increased costs due to regulation). }\end{array}$ \\
\hline
\end{tabular}

${ }^{a}$ Assessed by risk experts on a scale of 1-9.

b Data generated from Nexis data base.

cRated by University of Oregon students on a scale of 1-7 or 0-8.

${ }^{d}$ Rated by University of Oregon students on a scale of 0-8.

-Assessed by a Delphi panel of professionals on a scale of 0-10.

between individual intention to take action and potential social group mobilization was .52. In contrast, the variables within the two remaining classes (media coverage and societal impacts) were highly correlated. The correlation coefficients were .87 and .80 for the variables measuring media coverage and .89 for the two societal impact categories. This suggests that these variables within a class share a common underlying factor. 


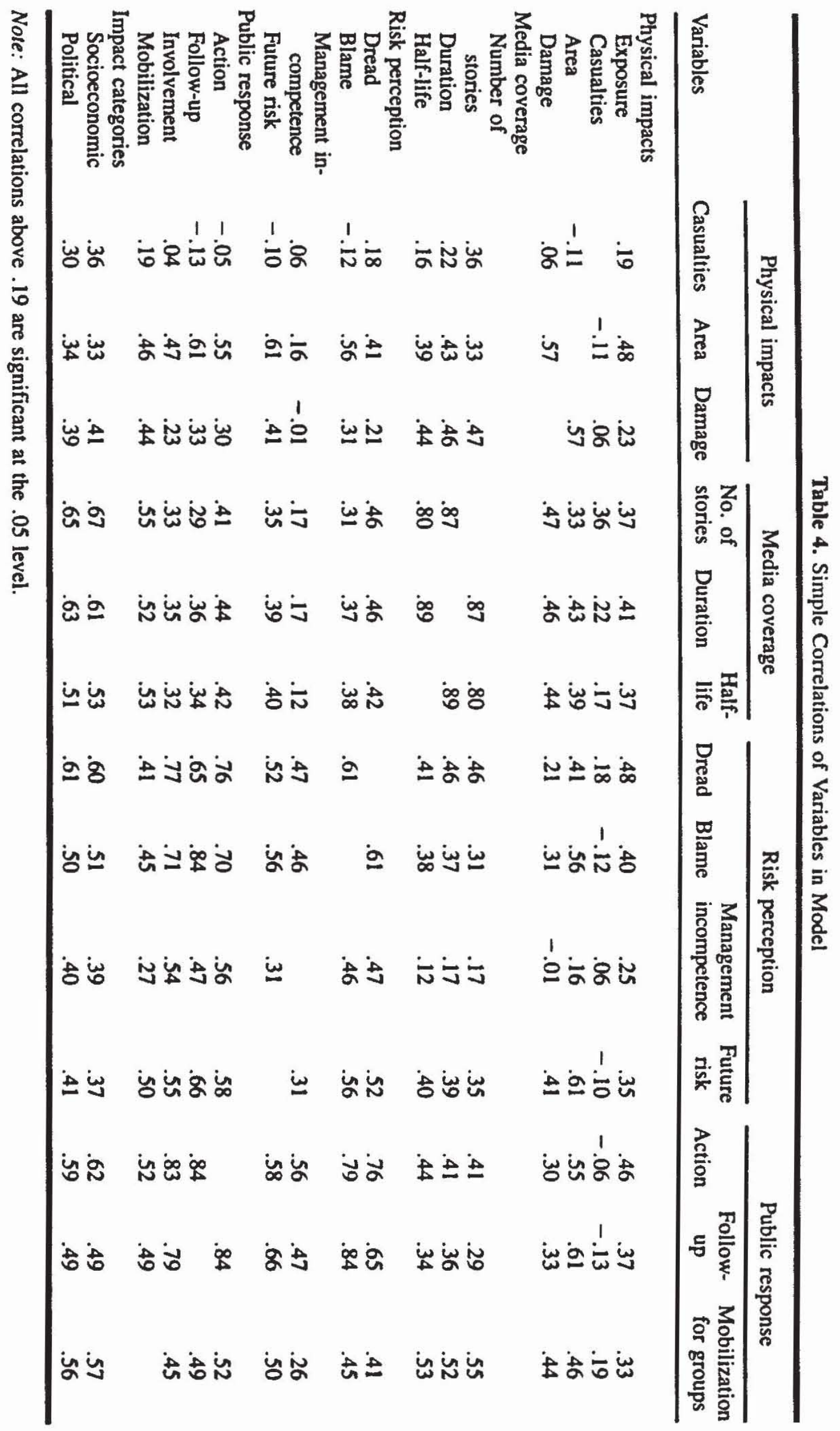


Examining the correlations between variables across classes provides some insight regarding the relationship among the theoretical concepts. The variables representing media coverage and the public response variables were more closely related to societal impact measures than either physical consequences or risk perception variables (except for dread). The risk perception variables were strongly related to the individual response measures, with correlations ranging from .47 to .84; and they were moderately related to mobilization potential ( $r=$ .27). The physical consequences, particularly the exposure variables, had an impact on both media coverage and responses. These correlations provided some evidence that the hypothetical model in Figure 2 was compatible with the data. The findings suggest that physical consequences are triggers for media coverage and-via perception-for public response, both of which generate societal impacts.

The individual response variables were less related to media coverage (range from .29 to .44) than was potential for social group mobilization ( $r=$ .55). The desire for future actions and the potential for one's own involvement appeared to depend more on specific components of the message than on mere quantity of coverage. Individual actions and mobilization potential were both highly correlated with societal impacts, suggesting that the social experience of risk is triggered by amplification processes on both the individual and social group levels.

Comparing the relationships of magnitude of casualties and extent of exposure to all other variables produced another interesting result. It was not the magnitude of a risk that was most influential in shaping the individual and social experience of risk, but the exposure to risk. The exposure to a hazard was a fairly good predictor for almost all other variable classes: media coverage, risk perception, public response, and societal impacts. Its correlations ranged between .25 and .48. In contrast to the extent of exposure, the actual number of human casualties was far less relevant for influencing risk experience. Most correlations between casualties and risk perception or public response were weak and below the level of significance $(r>.19)$. However, the magnitude of casualties influenced the amount of media coverage and societal impacts, and also exerted a modest influence on potential group mobilization.

These findings are particularly interesting because expert judgments on risks usually rely on estimates of expected fatalities rather than on exposure. These results show that individuals took exposure as their reference point, whereas the media and some social groups seemed to take into account both of these characteristics of hazard (though they also placed more emphasis on exposure). However, the fairly high correlations between the number of casualties and the magnitude of societal impacts suggest that human harm is also a major driver of societal impacts.

Interpreting these results, we must be aware that correlations do not imply 
causation. To investigate the size and direction of potential causal influences required testing the hypothetical model of social amplification using the multivariate procedures described above. This procedure examined the validity of the hypothetical model by comparing the predictions that emerged from the model against the correlations found in the data.

To test the hypothetical model as illustrated in Figure 2, we reduced the number of variables and selected only one or two variables to represent each class. Figure 3 illustrates the results of testing the hypothetical model using a covariance structure analysis program known as EQS. The coefficients in Figure 3 are path estimates, which represent linear relationships between two variables, holding constant the influence of other variables in the model. The overall fit of this model was extremely good (chi-square $=4.2, d f=6, p=.65$ ), indicating that its predictions were consistent with the data. The coefficients connecting property damage with societal impacts and number of stories with action were statistically insignificant, and thus were removed from the model. Likewise, the coefficients connecting casualties, property damage, and dread were deleted for the same reason.

For the most part, the path estimates confirmed the contentions put forth by the hypothetical model. Media coverage and individual responses exerted a direct and positive influence on societal impacts even when controlling for magnitude of casualties and extent of property damage. Dread influenced societal impact indirectly through its large effect on individual action. Media coverage had a strong link with both physical consequences and societal impacts. This indicates that the mass media reflect the actual damage and in turn generate societal impacts. Property damage affected societal impact only indirectly through its influence on media coverage and actions, whereas casualties had a small direct and a larger indirect effect on societal impacts. Our theoretical model did not suggest a direct link between casualties and societal impacts. However, this link was rather weak (.24), and it does not contradict our thesis that physical impacts are channeled through social amplification stations before they manifest themselves in societal impacts.

The lack of a causal link between media coverage and intended individual action is contrary to predictions from the social amplification framework. Furthermore, the simple correlation (cf. Table 4) between managerial incompetence and media coverage was also surprisingly low $(r=.17)$. This result appears implausible but can be explained if the meanings of the two variables are taken into account. Managerial incompetence and action are related to the content of information, not its quantity.

In order to gain more insight into the relationships between physical consequences, media coverage, and risk perception, the structural model in Figure 3 was modified to include exposure. The analysis of the simple correlation matrix indicated that exposure was more influential for people's perceptions than were magnitude of casualties or extent of property damage. We would expect, there- 


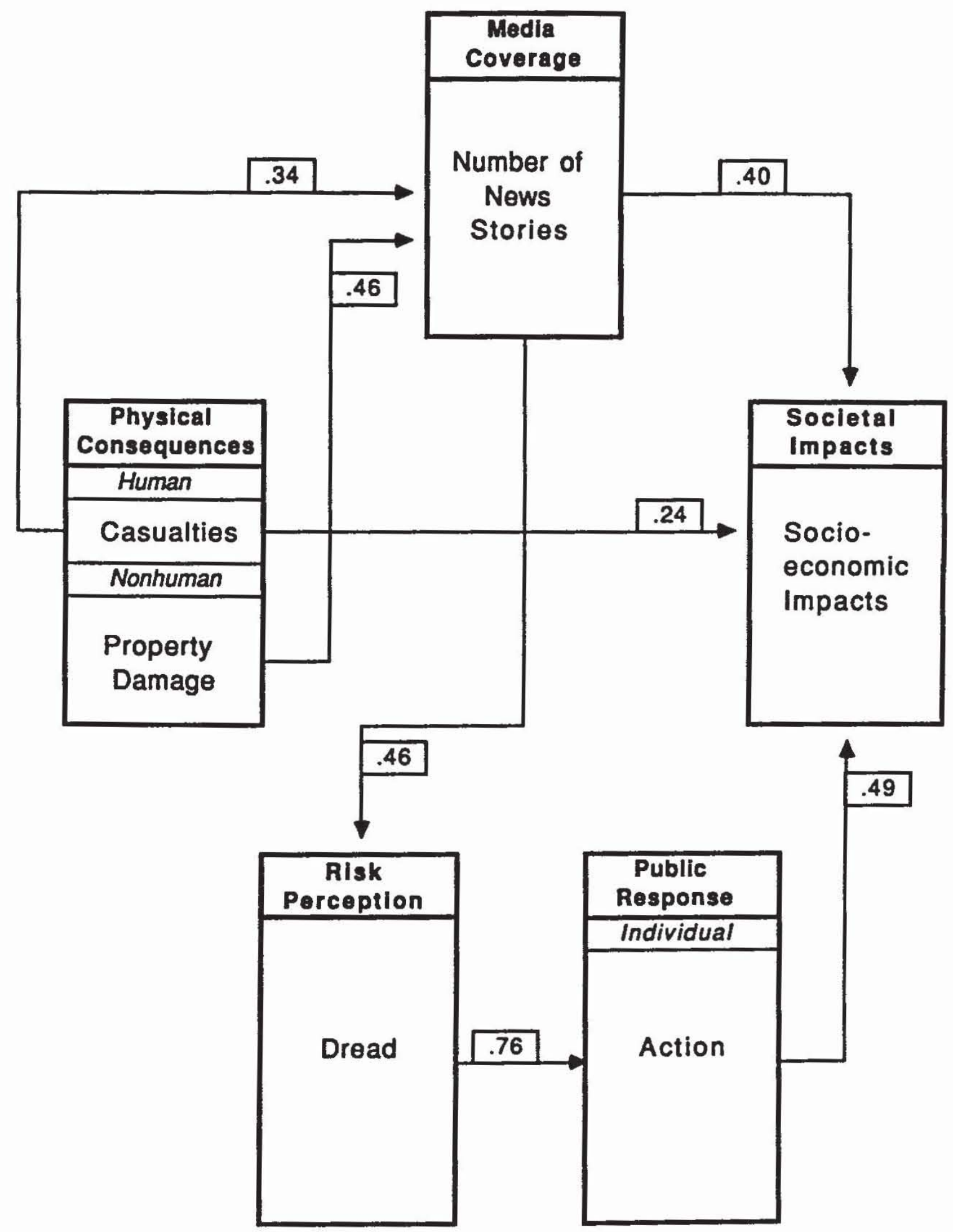

Fig. 3. Standardized regression coefficients among key variables.

fore, that exposure would be significantly linked to risk perception. Figure 4 illustrates the new model, including extent of exposure. The overall fit of this model was not as good as the model in Figure 3, but was still reasonable (chisquare $=17.91 ; d f=11, p=.08$ ). Exposure contributed to dread and was also positively related to media coverage. Its direct influence on intended action was 
small, indicating that exposure operated through risk perception variables to influence personal actions.

In the structural model, the link between exposure and societal impacts was not significant despite the initially high correlation between the two variables ( $r$ $=.48$ ). Exposure appears to shape societal impacts of risk through the media and through perceptions and intended individual actions. The pattern of relationships reflects the major assumption of the social amplification model-i.e., that physical events are observed and interpreted by groups and individuals, amplified through individual and social processors, and then expressed in terms of societal consequences.

Despite the inclusion of exposure in the model, the link between media coverage and dread still remained significant, although its coefficient decreased from .46 to .34 . This finding indicates that exposure failed to explain completely the association between media coverage and dread. This is plausible since exposure is not the only driver for media coverage; other aspects of the event, such as management errors or pending litigation, may also affect media coverage, and through this coverage, influence risk perception.

\section{Discussion and Conclusions}

The social amplification framework postulates that the social and economic impacts of an adverse event are determined not only by the direct physical consequences of the event, but by the interaction of psychological, cultural, social, and institutional processes that amplify or attenuate public experience of risk and result in secondary impacts. This concept was investigated by integrating in a single model key variables representing physical consequences, risk perceptions, media coverage, public responses, and societal impacts.

The overall picture emerging from this study revealed a remarkable amount of "rationality" in the social response to hazard events. The amount of press coverage is roughly proportional to the magnitude of physical impacts (particularly the scope of exposure). Risk perception incorporates exposure as well as risk management performance as basic elements of a risk judgment. Physical consequences of a hazard event have an effect on societal impacts, either directly (through casualties) or indirectly (through scope of exposure). Public responses, in turn, are influenced by exposure and risk perception.

The study yielded several other findings that may enhance the present knowledge about individual risk perception and the social processing of risk. First, individual and social risk experience appears more strongly related to exposure than to actual casualties, on which most risk assessments are based. Thus, an exposure of a few people resulting in several casualties is likely to be less influential for risk perception and public response than an exposure of many people that results in minor injuries or only a few casualties. For example, a cloud of toxic vapor traveling over a large populated area will have a much 


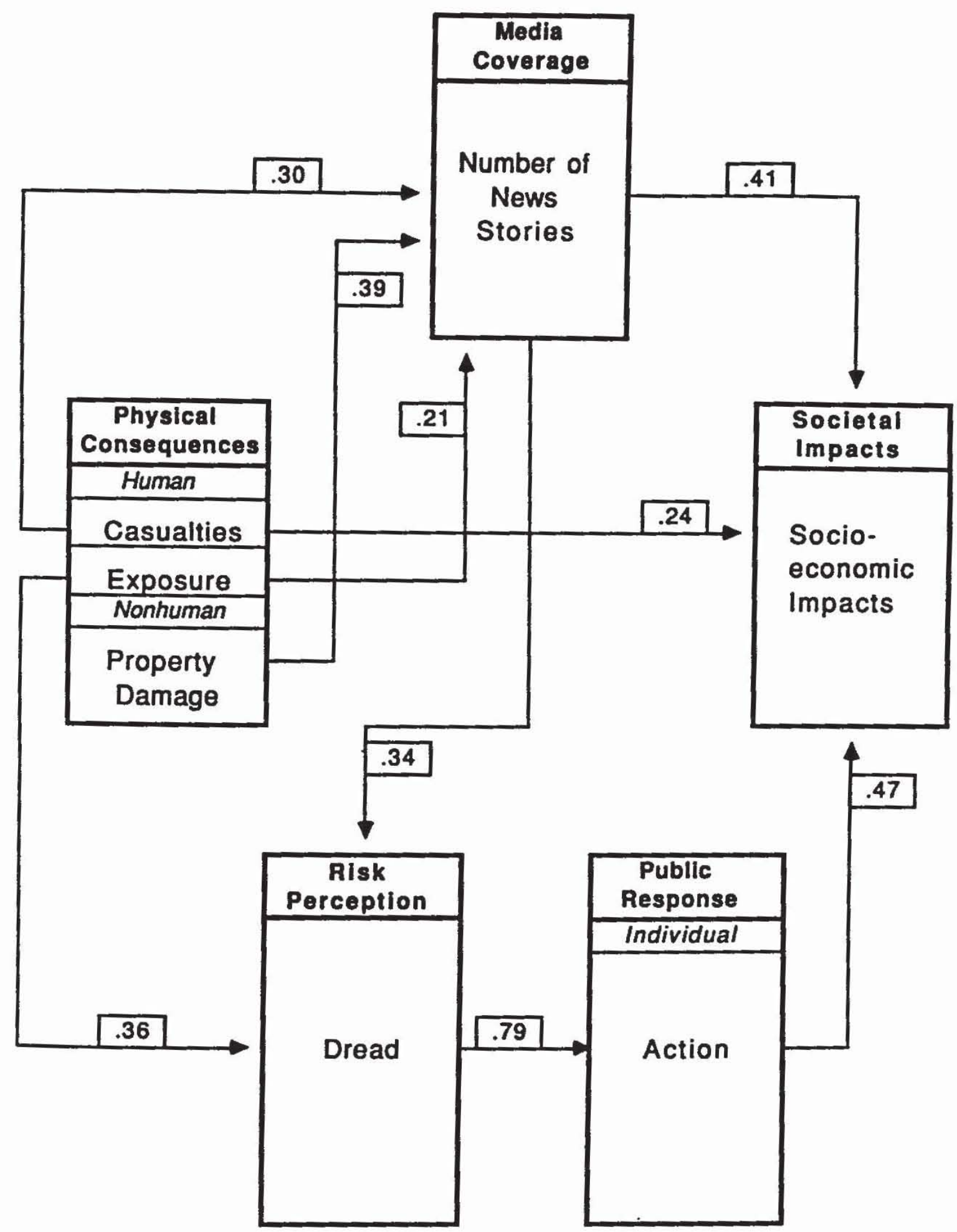

Fig. 4. Standardized regression coefficients including exposure.

stronger impact on individual and social amplification stations than an emission of toxic vapor in a confined building, even if more individuals are negatively affected in the second case.

This important conclusion needs further testing, but if supported by more studies, it may change the prevailing view about risk perception and social 
mobilization. It may be that the gap between expert judgments and laypersons' perceptions of risks as documented in the risk perception literature (Allen, 1987; Slovic, 1987) can only partially be explained by the effects of the qualitative risk characteristics, such as dread or familiarity. The gap may also be an expression of a different strategy for determining the seriousness of a hazard event. Experts use the magnitude of risk (weighted by the probability of occurrence) as a yardstick for risk evaluation, whereas most people appear to use exposure to risk as a major indicator for the perceived seriousness of risk.

Second, the processing of risk by the media, social groups, institutions, and individuals shapes the societal experience with risk, and plays a crucial role in determining the overall intensity and scope of societal impacts. In fact, our results suggest that press media coverage, perception of dread, and individual intentions to take action contribute substantially to an event's socioeconomic impacts, even when the extent of direct harm to people and property is controlled. The magnitude of physical consequences of an event also appears to influence societal impacts, but operates largely through intervening variables.

Third, events with widespread human exposure to risk received significantly more media coverage than events with low exposure. In addition, press coverage was moderately correlated with the number of casualties, and thus was clearly related to the physical impacts of hazardous events. Furthermore, the oftenexpressed hypothesis that risk perception is just a mirror of media coverage (see the discussion in Mazur, 1984, and Peltu, 1985) found little support in the moderate correlations between most risk perception variables and media coverage. Although dread was clearly related to media coverage, most of this effect could be explained by the intervening variable of exposure. All other perception variables showed moderate to small correlations with media coverage if the physical consequences were kept constant.

Fourth, among the perception variables, dread and blame were good predictors for behavioral intentions of individuals, and were moderately associated with group mobilization and societal impacts. Thus the societal impacts of risk experience seem less a product of biased and "chaotic" social processing of risks by amplification stations than of shaping and modifying risk judgments through a variety of factors that make sense. To include catastrophic potential and blame as factors for evaluating risks (in addition to expected harm) is intuitively plausible (Renn, 1990).

There are certain limitations of this study. The hazardous events were not chosen randomly, and the survey respondents were students of the University of Oregon rather than a sample of the U.S. population. Several variables, such as potential for social group mobilization and societal impacts, were assessed by expert ratings rather than by direct measurements, although we did attempt to gather as much objective data on them as possible. Our effort to test the data set 
for validity and reliability was limited by access to independent data verification or impeded by other constraints.

Our analysis is, therefore, preliminary, and needs further testing and refinement. We will continue to improve our models of the existing data set, and continue testing the validity and reliability of the data and the models. Despite the need for further investigations, this study already provides compelling evidence that points to a more rational and systematic societal response to risk than the past literature often suggested. More empirical research is needed to investigate the role of social amplification stations and their interactions with the media and with individuals.

If these empirical results can be replicated and validated, they will also provide strong evidence for the usefulness of the amplification concept. This theoretical approach has yielded some novel insights into the social processes that shape risk experience and impacts, and some of these may help change prominent beliefs of the scientific community about risk. The mere fact that the concept of social amplification has helped reveal these insights is an indication of its conceptual value.

\section{References}

Allen, F. W. (1987). Towards a holistic appreciation of risk: The challenge for communicators and policymakers. Science, Technology, and Human Values, 12, 138-143.

Beck, U. (1986). Die Risikogesellschaft: Auf dem Weg in eine andere Moderne. Frankfurt am Main: Suhrkamp.

Bradbury, J. A. (1989). The policy implications of differing concepts of risk. Science, Technology, and Human Values, 14, 380-399.

Burns, B. (1991). Introducing structural models and influence diagrams into risk perception research: Their value for theory construction and decision making. Unpublished dissertation, University of Oregon.

Clarke, L. (1989). Acceptable risk: Making decisions in a toxic environment. Berkeley: University of California Press.

Covello, V. T. (1983). The perception of technological risks: A literature review. Technological Forecasting and Social Change, 23, 285-297.

Dietz, T., Stern, P. C., \& Rycroft, R. W. (1989). Definitions of conflict and the legitimation of resources: The case of environmental risk. Sociological Forum, 4, 47-69.

Douglas, M., \& Wildavsky, A. (1982). Risk and culture. Berkeley: University of California Press.

Fornell, C. (1987). A second generation of multivariate analysis: Classification of methods and implications for marketing research. Review of marketing '87 (Section 6). Chicago: American Marketing Association.

Fornell, C., \& Bookstein, F. L. (1982). Two structural equation models: LISREL and PLS applied to consumer exit-voice theory. Marketing Research, 19, 440-452.

Freudenburg, W. R. (1988). Perceived risk, real risk: Social science and the art of probabilistic risk assessment. Science, 242, 44-49.

Freudenburg, W. R. (1989, October). The organizational attenuation of risk estimates. Paper presented at Society for Risk Analysis meeting, San Francisco.

Gould, L. C., Gardner, G. T., DeLuca, D. R., Tiemann, A., Doob, L. W., \& Stolwijk, J. A. J. (1988). Perceptions of technological risks and benefits. New York: Russell Sage Foundation.

Hohenemser, C., Kates, R. W., \& Slovic, P. (1983). The nature of technological hazard. Science, $220,378-384$. 
Johnson, B. B. (1987). The environmentalist movement and grip/group analysis: A modest critique. In V. T. Covello \& B. B. Johnson (Eds.), The social and cultural construction of risk (pp. 147-178). Dordrecht, The Netherlands: Reidel.

Kahneman, D., \& Tversky, A. (1979). Prospect theory: An analysis of decision under risk. Econometrica, 47, 263-291.

Kasperson, R. E., \& Kasperson, J. S. (1983). Determining the acceptability of risk: Ethical and policy issues. In T. J. Rogers \& D. V. Bates (Eds.), Assessment and perception of risk to human health (pp. 135-155). Ottawa: Royal Society of Canada.

Kasperson, R. E., Renn, O., Slovic, P., Brown, H. S., Emel, J., Goble, R., Kasperson, J. S., \& Ratick, S. (1988). The social amplification of risk: A conceptual framework. Risk Analysis, $8,177-187$.

Kasperson, R. E., Renn, O., Slovic, P., Kasperson, J. S., \& Emani, S. (1989). Social amplification of risk: The media and public response. In R. G. Post (Ed.), Waste management '89: Waste processing, transportation, storage, and disposal. Vol. 1: High-level waste and general interest (pp. 131-135). Tucson: University of Arizona Press.

Lee, T. R. (1986). Effective communication of information about chemical hazards. The Science of the Total Environment. 51, 149-183.

Luhmann, N. (1986). Okologische Kommunikation. Opladen: Westdeutscher Verlag.

Luhmann, N. (1990). Technology, environment, and social risk: A system perspective. Industrial Crisis Quarterly, 4, 223-231.

Machlis, G. E., \& Rosa, E. A. (1990). Desired risk: Broadening the social amplification of risk framework. Risk Analysis, 10, 161-168.

MacLean, D. (1987). Understanding the nuclear power controversy. In H. T. Engelhardt, Jr., \& A. L. Caplan (Eds.), Scientific controversies: Case studies in the resolution and closure of disputes in science and technology (pp. 567-582). Cambridge: Cambridge University Press.

May, P. J. (1989). Social science perspective: Risk and disaster preparedness. Mass Emergencies and Disasters, 7, 281-303.

Mazur, A. (1984). The journalist and technology: Reporting about Love Canal and Three Mile Island. Minerva, 22, 45-66.

Needleman, C. (1987). Ritualism in communicating risk information. Science, Technology, and Human Values, 12, 20-25.

Nelkin, D. (1982). Blunders in the business of risk. Nature, 298, 775-776.

Otway, H. J., \& von Winterfeldt, D. (1982). Beyond acceptable risk: On the social acceptability of technologies. Policy Sciences, 14, 247-256.

Peltu, M. (1985). The role of communications media. In H. Otway \& M. Peltu (Eds.), Regulating industrial risks (pp. 128-148). London: Butterworth.

Perrow, C. (1984). Normal accidents: Living with high risk technologies. New York: Basic Books.

Rayner, S. (1987). Risk relativism in science for policy. In V. T. Covello \& B. B. Johnson (Eds.), The social and cultural construction of risk (pp. 5-23). Dordrecht, The Netherlands: Reidel.

Rayner, S., \& Cantor, R. (1987). How fair is safe enough? The cultural approach to societal technology choice. Risk Analysis, 7, 3-13.

Renn, O. (1983). Technology, risk, and public perception. Angewandte Systemanalyse/Applied Systems Analysis, 4, 50-65.

Renn, O. (1984). Risikowahrnehmung der Kernenergie. Frankfurt am Main: Campus.

Renn, O. (1990). Risk perception and risk management: A review. Risk Abstracts, 7, 1-9; 8, 1-9.

Renn, O. (1991). Risk communication and the social amplification of risk. In R. Kasperson \& P. J. Stallen (Eds.), Communicating risk to the public (pp. 287-324). Dordrecht, The Netherlands. Kluwer.

Schwarz, M., \& Thompson, M. (1990). Divided we stand: Redefining politics, technology, and social choice. Philadelphia: University of Pennsylvania Press.

Short, J. F. (1984). The social fabric of risk: Toward the social transformation of risk analysis. American Sociological Review, 9, 711-725.

Short, J. F. (1989). On defining, describing, and explaining elephants (and reactions to them): Hazards, disasters, and risk analysis. Mass Emergencies and Disasters, 7, 397-418. 
Slovic, P. (1987). Perception of risk. Science, 236, 280-285.

Webler, T., Levine, D., Rakel, H., \& Renn, O. (in press). The group Delphi: A novel attempt at reducing uncertainty. Technological Forecasting and Social Change.

ORTWIN RENN is Associate Professor for Environment, Technology, and Society at Clark University in Worcester, Massachusetts, and a senior investigator at the Clark Center for Technology, Environment, and Development (CENTED), an interdisciplinary research institute devoted to the study of hazards and risks in contemporary societies. Previously he directed a research unit for technology assessment in the governmental research center in Julich, Germany. He received an M.A. degree in sociology and economics (European Diploma) and a doctorate in social psychology from the University of Cologne, and he has published seven books and more than 50 articles on topics related to technology.

WILLIAM J. BURNS received his Ph.D. from the University of Oregon in 1990 and is now Assistant Professor of Marketing at the University of lowa. His dissertation focused on incorporating risk perceptions into the management of hazardous technologies, and was supported by two National Science Foundation grants. His research interests also include the relationship between description and prescription in decision analysis.

JEANNE X. KASPERSON is Research Librarian and Director of Publications at CENTED, and is currently developing a research library for the World Hunger Program at Brown University, where she is Senior Research Associate. She has participated in numerous research projects, most recently on the social amplification of risk and the value issues attendant on transferring hazardous technologies to developing countries, and she has published five books and numerous articles.

ROGER E. KASPERSON holds a Ph.D. from the University of Chicago and is co-author or co-editor of Participation, Decentralization and Advocacy Planning, The Structure of Political Geography, Water Re-Use and the Cities, Equity Issues in Radioactive Waste Management, Nuclear Risk Analysis in Comparative Perspective, Corporate Management of Health and Safety Hazards: A Comparison of Current Practice, Understanding Global Environmental Change: The Contributions of Risk Analysis and Risk Management, and Communicating Risk to the Public. For the past ten years, he has directed a series of research projects, funded by the National Science Foundation, the Russell Sage Foundation, and the United Nations University, dealing with technological risk management, industrial management of hazards, and ethical and policy issues involved in risk management. 
PAUL SLOVIC is President of Decision Research in Eugene, Oregon, and a professor of psychology at the University of Oregon. During the past 15 years, he and his associates have developed methods for describing risk perceptions and measuring their impacts on individuals, industry, and society. He is a member of the National Council on Radiation Protection and Measurements and a past president of the Society for Risk Analysis. 